\title{
Processo de desligamento entre Pesquisadores e PARTICIPANTES NA PESQUISA-AÇÃO ${ }^{\star}$
}

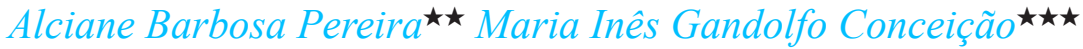

Resumo

Objetiva-se discutir teoricamente a temática do processo de desligamento no contexto da pesquisa-ação. Realizou-se um estudo teórico acerca da temática do desligamento nas obras de René Barbier, Michel Thiollent, David Tripp, André Morin e Hugues Dionne. As análises apontam para a relevância dada ao início da pesquisa e da implicação e vinculação entre os participantes e pesquisadores em detrimento do processo final. Constata-se que os autores discutem menos sobre o processo de separação entre pesquisadores e participantes e que a fase final da pesquisa caracteriza-se como uma etapa de avaliação dos resultados, teorização, escrita em conjunto do relatório final, publicação, divulgação dos resultados, na qual os participantes permanecem em situação ativa.

Palavras-chave: Processo de desligamento; pesquisa-ação; implicação.

\section{SHUTDOWN PROCESS BETWEEN RESEARCHERS AND PARTICIPANTS IN ACTION RESEARCH}

\begin{abstract}
The aim is to discuss theoretically the issue of the disconnection process in the context of action research. A theoretical study about it was conducted in the works of Rene Barbier, Michel Thiollent, David Tripp, André Morin and Hugues Dionne. The analyses reveal the importance given to the starting point of the research as well as to the involvement and bonding among participants and researchers rather than to the final process. It was observed that the authors discuss less about the separation process between researchers and participants. Furthermore, it was observed that the phase towards the end of the research is characterized as a stage of results evaluation, theorizing, group writing the final report, publication, and results releasing, in which the participants remain in active status.

Keywords: Shutdown process; Action Research; Implication.

^ Fonte de Financiamento: Coordenação de Aperfeiçoamento de Pessoal de Nível Superior (CAPES)

$\star \star$ Psicóloga. Mestre e doutoranda em Psicologia Clínica e Cultura pela Universidade de Brasília. Atualmente é psicóloga no Departamento de Desenvolvimento de Recursos Humanos da Universidade Federal de Goiás e professora convidada na Pontifícia Universidade Católica de Goiás. E-mail: alcianebarbosa@gmail.com

$\star \star \star$ Psicóloga. Doutora em Psicologia pela Universidade de Brasília, pós-doutora pela Universidade Federal Fluminense, realiza Estágio Sênior (bolsista CAPES) na University of Toronto (2012). Atualmente é Professora Adjunta IV do Instituto de Psicologia da Universidade de Brasília. Endereço: Universidade de Brasília, Instituto de Psicologia. Campus Universitário Darcy Ribeiro - Asa Norte. Brasilia, DF - Brasil - Caixa-postal: 04500. CEP: 70910-900.

E-mail: inesgand@unb.br
\end{abstract}


Surgida há mais de 50 anos, a abordagem em Ciências Sociais denominada pesquisa-ação, hoje está presente em trabalhos de várias áreas da psicologia: escolar, clínica, comunitária, social, entre outras. É necessário, no entanto, um aprofundamento sobre essa forma de fazer pesquisa e uma postura metodológica isenta de modismos.

Este artigo objetiva a discussão teórica da temática do processo de desligamento no contexto da pesquisa-ação, visto que a relação pesquisador/participante na realidade desse tipo de metodologia se diferencia das demais, principalmente pela proximidade e vinculação que se estabelecem entre os envolvidos. Dessa forma, realizou-se um estudo teórico acerca da temática do desligamento entre participantes e pesquisadores nas obras sobre pesquisa-ação de autores atuais. Um estudo desse tipo se justifica devido ao crescimento da utilização do método da pesquisa-ação nos diferentes contextos e a ética necessária em todos os momentos da pesquisa, particularmente na fase final que deve promover autonomia entre os participantes.

A compreensão acerca do processo de desligamento, no entanto, está relacionada à contextualização da própria pesquisa-ação. Para isso, antes é preciso situá-la como método de pesquisa, apresentar os principais conceitos na atualidade e caracterizar o processo de construção da pesquisa na visão dos diferentes autores estudados. Discutidas essas informações, é possível aprofundar acerca da relação pesquisador-participante e posteriormente, do processo de desligamento no contexto da pesquisa-ação.

\section{HistóRIA E PRINCIPAIS CONCEITOS}

A abordagem da pesquisa-ação foi desenvolvida principalmente a partir dos estudos realizados nos Estados Unidos. O francês René Barbier (2007) é professor de Ciências da Educação e para ele, essa forma de pesquisa não trata de uma simples transfiguração metodológica da sociologia clássica, mas de uma transformação na forma de se conceber e fazer pesquisa em Ciências Humanas, em que o cotidiano não é excluído do processo de construção do conhecimento.

A atribuição mais comum ao surgimento do termo "pesquisa-ação" na literatura é ao psicólogo e pesquisador experimental de origem alemã Kurt Lewin (1946, apud TRIPP, 2005). Quase imediatamente após ser cunhada a terminologia na literatura, a pesquisa-ação esteve relacionada a quatro processos diferentes: pesquisa-diagnóstico, pesquisa-participante, pesquisa empírica e pesquisa experimental (TRIPP, 2005). Sobre a questão do surgimento da pesquisa-ação, Barbier (2007) também reconhece ser de autoria de Kurt Lewin, durante a Segunda Guerra Mundial, e complementa que a origem também é atribuída por alguns a John Dewey e ao movimento da Escola Nova, após a Primeira Guerra Mundial. A suposição é de que esse movimento constituiu um primeiro tipo de pesquisa-ação pelo ideal democrático, pelo pragmatismo e pela insistência no hábito do conhecimento científico tanto nos educadores como nos educandos (THIRION, 1980 apud BARBIER, 2007). Outra possível origem da pesquisa-ação é apresentada por Georges Lapassade que atribui a criação do termo pesquisa-ação ao antro- 
pólogo John Collier, o qual propôs que as descobertas de tipo etnológico, feitas nos EUA sobre indígenas das reservas, fossem utilizadas em benefício de uma política favorável aos mesmos (LAPASSADE, 1991, apud BARBIER, 2007).

Segundo Barbier (2007), após a Segunda Guerra Mundial, a pesquisa-ação foi disseminada no Japão, Inglaterra, Alemanha e França. Mas é no Canadá, Inglaterra e França, a partir dos anos 1970, que se acentua a tendência mais radical. $\mathrm{O}$ autor destaca no processo de radicalização epistemológica da pesquisa-ação, dois períodos: 1) o período mais americano, de emergência e consolidação entre os anos que precedem a Segunda Guerra Mundial e os anos de $1960 ; 2$ ) o período de radicalização política e existencial, mais europeu e canadense, desde o final dos anos 1960 até os nossos dias.

De acordo com o professor da área de Engenharia da Produção da Universidade Federal do Rio de Janeiro, o francês Michel Thiollent (1996), as áreas de aplicação da pesquisa-ação são: educação; comunicação; serviço social; organização e sistemas; desenvolvimento rural; difusão de tecnologia; práticas políticas, entre outras. Thiollent (2007) também chama a atenção para o fato de que a pesquisa-ação, por mais que tenha sido difundida nas áreas das Ciências Humanas, recebe um crescente interesse em áreas consideradas mais técnicas, tais como a engenharia da produção, a ergonomia, arquitetura, agronomia, entre outras. Na psicologia, atualmente a pesquisa-ação ganhou espaço em trabalhos no contexto da psicologia escolar, psicologia clínica, psicologia comunitária, psicologia social a partir de diferentes concepções, o que demanda maior investimento em relação à construção de conhecimento sobre práticas investigativas por meio da pesquisa-ação que superem meros modismos.

Sobre a diversidade de denominações de pesquisa-ação, Thiollent (1996) aponta para a inexistência de unanimidade. Uma das "confusões" mais comuns é a que se estabelece entre as expressões "pesquisa participante" e "pesquisa-ação", frequentemente dadas como sinônimas. Para o autor, não o são: a pesquisa-ação, além da participação, supõe uma forma de ação planejada de caráter social, educacional, técnico ou outro, que nem sempre é encontrada em propostas de pesquisa participante. Thiollent (1996), no entanto, afirma que tanto a pesquisa-ação e a pesquisa participante procedem da mesma busca de alternativas ao padrão de pesquisa tradicional.

Sobre a diferença entre pesquisa-ação e pesquisa participante, Demo (2004), pesquisador defensor da pesquisa participante (PP), afirma que a "pesquisa-ação" surgiu devido à dificuldade de se atingir níveis elevados de participação, porque ela "resigna-se mais facilmente a apenas propor ações com algum conhecimento de causa" (DEMO, 2004, p. 101). O autor considera que tal "característica" não retira o mérito da pesquisa-ação e argumenta que, do ponto de vista do pesquisador é uma forma mais fácil de assumir a pesquisa-ação, do que a pesquisa participante. Ao contrário do que afirma Demo (2004), o ato de meramente "propor ações", no entanto, não condiz com a forma como a pesquisa-ação se desenvolve para os outros autores estudados neste trabalho, uma vez que eles enfatizam a construção de ações a partir da participação dos atores envolvidos. 
Demo se apropria da definição de Pesquisa Participante, de Budd Hall (1981 apud DEMO, 1987), que a descreve como uma atividade integrada que combina investigação social, trabalho educacional e ação. A ação nesta perspectiva de pesquisa é entendida semelhantemente ao que se considera em relação à pesquisa-ação e tem por objetivo a mudança, que por sua vez, está relacionada à resolução da problemática levantada. Sobre esta proximidade, Thiollent (1987) descreve que a pesquisa-ação pode ser considerada uma forma de pesquisa participante, mas afirma que nem todas as pesquisas participantes são pesquisa-ação, justamente por nem todas terem por objetivo a mudança a partir da proposta de ações junto aos participantes.

De acordo com Thiollent (1987), a pesquisa participante teve como foco o investigador dentro da situação investigada e chegou a problematizar a relação estabelecida entre pesquisador e pesquisado. Entretanto, segundo o autor, os pesquisadores que partiam da pesquisa participante não voltaram de maneira contínua sua atenção para a relação entre investigação e ação na situação considerada. Brandão (1987), outra importante referência sobre a Pesquisa Participante, no entanto, afirma que a relação de participação da prática científica no trabalho político das classes populares desafia o pesquisador a ver e compreender os sujeitos e seus contextos, por meio das pessoas e de um trabalho social e político, intencionalmente participativo, que se trata da razão de ser da pesquisa participante, $o$ que supostamente para o autor não é contemplado na perspectiva da pesquisa-ação, da mesma maneira que na pesquisa-participante. Discordâncias a parte, tanto a pesquisa-ação quanto a pesquisa participante têm como característica algo que ainda não está presente em muitos dos outros métodos de pesquisa: o compromisso social, seja com o foco na participação, seja na busca pelas mudanças a partir da construção conjunta de ações.

Há também outras "confusões" comuns relacionadas à pesquisa-ação. Segundo Thiollent e Silva (2007), enquanto método de pesquisa, a pesquisa-ação também não deve ser confundida com outros métodos participativos, cujas características e finalidades são diferentes. É o caso de técnicas de planejamento, monitoramento ou avaliação.

Uma forma de diferenciar a pesquisa-ação de outras formas de investigação é conhecer quais definições existem a respeito desse método. A pesquisa-ação é definida por Tripp (2005) como uma das diferentes formas de investigação-ação que tem como objetivo final aprimorar a prática. Optando por uma definição mais estrita, o autor denomina a pesquisa-ação como uma forma de investigação-ação que utiliza técnicas de pesquisa consagradas para informar a ação que se decide tomar para melhorar a prática, de forma que as técnicas de pesquisa atendam aos critérios comuns a outros tipos de pesquisa acadêmica. Tripp (2005) postula ainda dez características da pesquisa-ação: inovadora; contínua; pro-ativa estrategicamente; participativa; intervencionista; problematizada; deliberada; documentada; compreendida; e disseminada. 
Thiollent (1996), por sua vez, define a pesquisa-ação como uma forma de se fazer pesquisa social com base empírica que é concebida e realizada em estreita associação com uma ação ou com a resolução de um problema coletivo. Para ele, em todo o processo, os pesquisadores e os participantes representativos da situação ou do problema estão envolvidos de modo cooperativo ou participativo. $\mathrm{O}$ autor apresenta a pesquisa-ação como uma estratégia metodológica da pesquisa social na qual:

a) Há uma ampla e explícita interação entre pesquisadores e pessoas implicadas na situação investigada;

b) Desta interação resulta a ordem de prioridade dos problemas a serem pesquisados e das soluções a serem encaminhadas sob forma de ação concreta;

c) O objeto de investigação não é construído pelas pessoas e sim pela situação social e pelos problemas de diferentes naturezas encontrados nesta situação;

d) O objetivo da pesquisa-ação consiste em resolver ou, pelo menos, esclarecer os problemas da situação observada;

e) Há, durante o processo, um acompanhamento das decisões, das ações e de toda a atividade intencional dos atores da situação;

f) A pesquisa não se limita a uma forma de ação (risco de ativismo): pretende-se aumentar o conhecimento dos pesquisadores e do conhecimento ou o "nível de consciência" das pessoas e grupos considerados. (THIOLLENT, 1996, p. 16).

Em perspectiva semelhante, o sociólogo canadense Dionne (2007) caracteriza a pesquisa-ação como instrumento de "intervenção" na realidade circundante dos pesquisadores, em parceria com os atores implicados em determinadas situações problemáticas. Em conjunto, pesquisadores e atores promovem ações para transformar a situação inicial em uma situação desejada. As diferentes definições de pesquisa-ação para o autor, têm em comum a importância do vínculo que une os pesquisadores e os atores ou profissionais e cinco importantes dimensões podem ser extraídas da variedade das definições de pesquisa-ação:

1. Fortalecimento da relação entre a teoria e a prática;

2. Fortalecimento das alianças e comunicações entre pesquisadores e atores;

3. Perseguição de um duplo objetivo de conhecimentos a desenvolver (pesquisa) e de situações a modificar (ação); 
4. Produção de um novo saber na ação e para a ação;

5. Inserção em um processo de tomada de decisão com vistas à resolução de problemas (DIONNE, 2007, p. 46).

De acordo com Thiollent (1996), cuja definição de pesquisa-ação é aqui defendida, o objetivo da pesquisa-ação consiste em dar aos pesquisadores e grupos de participantes os meios de se tornarem capazes de responder com maior eficiência aos problemas da situação em que vivem, em particular sob forma de diretrizes de ação transformadora. Mesmo considerando como relevante o lado empírico, essa abordagem nunca deve deixar de colocar as questões relativas aos quadros de referência teórica no processo investigativo, sem os quais a pesquisa empírica de pesquisa-ação não faria sentido algum. A seguir, será apresentado o percurso metodológico em pesquisa-ação para os autores estudados.

\section{A CONSTRUÇÃo da PESQUiSA-AÇÃo}

A pesquisa-ação é uma metodologia ou um método? Pergunta respondida por Thiollent (1996) quando aponta que a pesquisa-ação não é considerada uma metodologia. Ela é um método ou uma estratégia de pesquisa que agrega várias técnicas de pesquisa social, com os quais se estabelece uma estrutura coletiva, participativa e ativa ao nível da captação de informação. De acordo com o autor, os autores de metodologia de pesquisa em ciências sociais definem a pesquisa-ação como qualquer outro método. Dessa forma, as ciências sociais tomam a pesquisa-ação como objeto para analisar suas qualidades, potencialidades, limitações e distorções. A metodologia oferece subsídios de conhecimento geral para orientar a concepção da pesquisa-ação e controlar o seu uso. A pesquisa-ação é um método de pesquisa que possui diferentes técnicas particulares em cada fase ou momento do processo investigativo.

De acordo com Barbier (2007, p. 118), há quatro temáticas centrais no método da pesquisa-ação:

1. A identificação do problema e a contratualização;

2. O planejamento e a realização em espiral, ou seja, de maneira não linear;

3. As técnicas da pesquisa-ação (particularmente a denominada observação participante predominantemente existencial e o diário de itinerância);

4. A teorização, a avaliação e a publicação dos resultados.

O educador canadense André Morin (2004), por sua vez, afirma que a pesquisa-ação tem por finalidade servir de instrumento aberto de mudança social. Por isso, em todas as fases do ciclo que a constitui, apresentadas por Barbier (2007), os membros do grupo (os atores sociais) devem participar ativamente, uma vez 
que estão em melhores condições de conhecer a sua realidade do que as pessoas que não pertencem ao grupo. Dessa forma, o meio de trabalho do profissional envolvido parece se aproximar mais da abordagem clínica e de um estudo de caso.

Na perspectiva apresentada, Morin (2004) propõe a Pesquisa-ação Integral e Sistêmica (PAIS) como uma metodologia que se utiliza do pensamento sistêmico para trabalhar com um fenômeno complexo, ativo em um ambiente igualmente em evolução, no intuito de permitir a um ator coletivo intervir nesse ambiente para viabilizar a mudança. $\mathrm{O}$ autor descreve que a escolha da metodologia da PAIS deve se dar a partir das seguintes ações:

1. Conhecer a natureza da problemática;

2. Descobrir a necessidade de participação e a natureza dos problemas;

3. Garantir a finalidade de mudança e dos modos de participação;

4. Dar-se uma linguagem comum entre pesquisadores e participantes;

5. Realizar um contrato aberto, formal e não-estruturado (MORIN, 2004, p. 115-119).

Quanto às modalidades de expressão para registrar informações ligadas ao processo iterativo de uma PAIS, Morin (2004) destaca o diário de bordo, as atas de reunião, gravações, entrevistas e questionários e as técnicas de redação coletiva. Durante e posteriormente às ações, o autor apresenta as seguintes fases: observação; classificação; conclusões, que também são realizadas em conjunto nessa abordagem.

Ainda acerca das fases da pesquisa-ação, de acordo com Tripp (2005), o ciclo desse método investigativo se inicia com um reconhecimento que corresponde a uma análise situacional que produz ampla visão do contexto, práticas atuais dos participantes e envolvidos. Na pesquisa-ação, uma das principais características é a interação entre os envolvidos. Além disso, destaca-se a reflexão, a relação entre a teoria e a prática e o compromisso ético. O autor assinala ainda os epiciclos: "Planejamento", como primeiro passo para a ação; "Implementação"; "Relatório de Pesquisa", sobre os resultados da melhoria planejada; "Avaliação", da mudança na prática e da pesquisa.

Dionne (2007), por sua vez, apresenta quatro fases principais do processo de pesquisa-ação: a "Identificação das situações iniciais", seguida da "Projetação da pesquisa" e da ação, a "Realização das atividades" previstas e a "Avaliação dos resultados". Thiollent (2007) percebe que este esquema tem origem em uma concepção pragmática de métodos de resolução de problemas (Problem solving). 
Ainda sobre o planejamento de uma pesquisa-ação, Thiollent (1996) o descreve como algo muito flexível, pois não segue uma série de fases rigidamente ordenadas. A apresentação de temas para o desenvolvimento da pesquisa-ação só é possível se há a consideração de que existe durante a pesquisa um vai e vem e um entrelaçamento entre eles. Conhecido isso, é possível compreender o processo da pesquisa-ação.

De maneira mais detalhada que os demais autores, Thiollent (1996) afirma que a primeira temática que compõe a sua proposta de pesquisa-ação é a "fase exploratória", a qual tem por objetivo descobrir o campo de pesquisa, os interessados e suas expectativas, e estabelecer um primeiro levantamento da situação, dos problemas prioritários e de eventuais ações. Outra temática é a "escolha do tema" da pesquisa, como um tipo de compromisso entre a equipe de pesquisadores e os elementos ativos da situação a ser investigada. Há também a "colocação dos problemas", de acordo com o marco teórico-conceitual adotado. Além disso, é importante "definir o lugar da teoria" como fonte de geração de ideias, hipóteses, ou diretrizes para orientar a pesquisa e as interpretações e a "construir de maneira suavizada as hipóteses de investigação" (THIOLHENT, 1996, p. 56). Outros temas relevantes para Thiollent (1996) são: "construção do plano de ação"; "percepção quanto a capacidade de aprendizagem", que aqui está associada ao processo de investigação; "estudo da relação entre saber formal e saber informal" a fim de estabelecer (ou melhorar) a estrutura de comunicação entre os dois universos culturais (dos pesquisadores e dos interessados). Somado a isso, há a "delimitação de observação, amostragem e representatividade qualitativa", a "coleta de dados" e a "realização do seminário", que tem por função examinar, discutir e tomar decisões acerca do processo de investigação, no qual se centralizam as informações coletadas e se discutem as interpretações. Por fim, existe a "divulgação externa", além do retorno da informação aos grupos implicados. Essa descrição dos temas que constituem a pesquisa-ação, de acordo com a proposta de Thiollent (1996), é particularmente importante para a compreensão acerca da construção da pesquisa-ação.

Torna-se relevante destacar que para os diferentes autores estudados então presentes na proposta da pesquisa-ação, de maneira mais ou menos detalhada, alguns elementos específicos durante todo o processo de pesquisa. Entre eles, de maneira interdependente, estão planejamento, ação, avaliação e de maneira transversal, reflexão junto a todos os autores nos diversos momentos.

É importante considerar também que ter a pesquisa-ação como referencial para a construção dos caminhos da pesquisa também envolve alguns riscos. Riscos discutidos pelas professoras da Faculdade de Educação da Universidade Federal de Goiás, Miranda e Resende (2006). De acordo com as autoras, o conceito de pesquisa-ação representa um dos grandes impasses sobre a relação entre a teoria e a prática. As autoras argumentam a respeito dos riscos inerentes à suposta resolução imediata da contradição entre a teoria e a prática pela metodologia da pesquisa-ação. Tais riscos correspondem à ingênua substituição do objetivismo característico da pesquisa clássica positivista pelo subjetivismo e a teoria pela prática. 
Thiollent (1996), por sua vez, afirma que é possível conceber dispositivos de pesquisa social com base empírica sem abandonar o espírito científico. Isto é possível quando, em vez da separação, há um tipo de co-participação dos pesquisadores e das pessoas implicadas no problema pesquisado. Para o autor, a substituibilidade dos pesquisadores não é total, pois o que cada pesquisador observa e interpreta nunca é independente da sua formação, dos seus referencias teóricos, de suas experiências anteriores e do próprio envolvimento na situação investigada. E mais: "O qualitativo e o diálogo não são anticientíficos" (THIOLLENT, 1996, p. 23).

Barbier (2007), por outro lado, aponta também alguns riscos que devem ser levados em conta na escolha do método da pesquisa-ação, por parte do pesquisador, sujeito ativo e implicado no processo de pesquisa:

- Riscos institucionais para aqueles que se preocupam com a carreira acadêmica. Ainda atualmente a pesquisa-ação está longe de ser o melhor caminho para ser rapidamente bem sucedido no mundo acadêmico. [...]

- $\quad$ Riscos pessoais porque a pesquisa-ação, na sua intersubjetividade, leva inevitavelmente o pesquisador para regiões de si mesmo que ele, sem dúvida, não tinha vontade de explorar (BARBIER, 2007, p. 33).

Dessa forma, o ato de pesquisar a partir do método da pesquisa-ação requer do pesquisador estudo, observação, reflexão e consciência da intencionalidade das suas ações. Conhecido um pouco acerca do processo investigativo em pesquisa-ação, faz-se necessário discutir a relação construída entre pesquisador e participantes, para assim realizar algumas considerações sobre o processo de desligamento.

\section{A RELAÇão PESQUiSAdOR-PARTICIPANTES NA PESQUiSA-AÇão}

A discussão acerca da impossibilidade da neutralidade na prática da pesquisa em ciências humanas viabilizou o surgimento de outras formas de fazer pesquisa distintas daquelas com base nos princípios positivistas e na referência das ciências naturais e exatas. Considerar a ausência da neutralidade científica é levar em conta a identidade entre sujeito e objeto nas pesquisas em ciências humanas. Os autores estudados consideram unanimemente a pesquisa-ação como representação fiel da impossibilidade do exercício da neutralidade. Nesse tipo de pesquisa é impossível que não aconteça uma construção diferenciada a depender da atividade dos diferentes sujeitos. Como afirma Thiollent (1996, p. 70): "Não há neutralidade por parte dos pesquisadores e dos atores da situação".

De acordo com Dionne (2007), desde as descobertas de Kurt Lewin sobre a pesquisa-ação, este afirmava que quando os sujeitos estão implicados em grupo na resolução dos problemas, há a constatação de modificações de comportamentos mais rapidamente. Segundo o autor, a implicação do pesquisador, sua permanente presença no campo pesquisado é central nesse tipo de procedimento. 
A tradição positivista, no entanto, nos acostumou ao "distanciamento" do pesquisador (DIONNE, 2007). A ausência da neutralidade científica no contexto da pesquisa-ação se deve à implicação dos atores e pesquisadores.

Ao aprofundar sobre o tema da implicação na pesquisa-ação, Barbier (1985) considera três níveis de abordagem do conceito de "implicação": o nível psicoafetivo; o nível histórico-existencial; e o nível estrutural-profissional. O nível psicoafetivo está presente na pesquisa-ação, uma vez que o objeto de investigação sempre questiona os fundamentos da personalidade profunda. Além disso, a implicação está presente em toda profissão em que se tem como base o desenvolvimento de relações humanas peculiares. O nível histórico-existencial está articulado ao primeiro nível, pois a pesquisa acontece também ligada à própria vida do pesquisador, à sua história, na qual a sua existência também está em jogo e em que ele trabalha o mais profundo dos seus problemas no momento. $\mathrm{O}$ autor complementa: "[...] é na medida que enfrento com seriedade os meus problemas que me torno mais disponível para os participantes" (BARBIER, 2007, p. 111). Já o nível estrutural-profissional corresponde à procura de elementos que têm sentido com referência ao trabalho social do pesquisador e o contexto sócio-econômico. Sobre esse último nível, o autor afirma que toda profissão apresenta um não-dito institucional. Este não-dito é a sua posição no campo das relações de produção e do sistema de valores que lhe dá coerência à própria profissão. Para Barbier (1985, p. 120), os diferentes níveis de implicação se interpenetram e agem um sobre o outro:

A implicação, no campo das ciências humanas, pode ser então definida como o engajamento pessoal e coletivo do pesquisador em e por sua práxis científica, em função de sua história familiar e libidinal, de suas posições passada e atual nas relações de produção e de classe, e de seu projeto sóciopolítico em ato, de tal modo que o investimento que resulte inevitavelmente de tudo isso seja parte integrante e dinâmica de toda atividade de conhecimento.

Franco (2005), pesquisadora da área da Educação, descreve que a consequência da imbricação entre pesquisa e ação é a participação do pesquisador no universo pesquisado. Isto anula a possibilidade de uma postura de neutralidade e de controle das circunstâncias da pesquisa.

A proximidade que viabiliza a realização da pesquisa-ação também abre espaço para a discussão de diferentes questões. Costa et al (2008), pesquisadoras da área da psicologia, que utilizam com frequência o método da pesquisa-ação, no contexto desse tipo de pesquisa em situações-limite de sofrimento, afirmam que a pesquisa-ação, inevitavelmente, possibilita a criação de um vínculo terapêutico positivo das famílias, de suas crianças e seus adolescentes entre si e com a equipe de trabalho. Às vezes, a vinculação traz situações difíceis de serem remanejadas pelos pesquisadores. 
Como possibilidade de reflexão acerca da problemática da implicação em pesquisa-ação, Barbier (2007) descreve que o pesquisador deve desempenhar seu papel profissional numa dialética que articula constantemente; implicação e distanciamento; a afetividade e a racionalidade; simbólico e imaginário; mediação e desafio; autoformação e heteroformação; ciência e arte. Dessa maneira, o autor em pesquisa-ação "[...] é antes de tudo um sujeito autônomo e, mais ainda, um autor de sua prática e de seu discurso" (BARBIER, 2007, p. 19).

A implicação em pesquisa-ação resulta também na relação entre geração de conhecimento e transformação. Dionne (2007) afirma que a tipologia de pesquisa-ação de Desroche permite distinguir os objetivos essenciais da pesquisa-ação a partir de duas tendências gerais: uma pesquisa com finalidade explicativa ou uma pesquisa com finalidade transformadora de dada situação. No primeiro caso, existe uma pesquisa-ação que valoriza principalmente a geração de conhecimentos. No segundo, a atenção se voltará principalmente para a eficácia da ação. E é pouco provável haver transformação sem implicação. De acordo com Morin (2004), o vínculo entre teoria e prática está na inseparabilidade da ação e do conhecimento. $\mathrm{O}$ ator em pesquisa-ação também se torna pesquisador, uma vez que nessa proposta é reduzida a distância entre ciência e ação (DIONNE, 2007). Dessa forma, a divisão social do trabalho profissional entre pesquisador e participante-ator tende a desvanecer-se, tornando-se um coletivo engajado em uma mesma intervenção. Ao apresentar a obra de Morin (1992 apud DIONNE, 2007), Dionne afirma que no contexto da pesquisa-ação cria-se uma relação incomum entre pesquisador implicado na ação e ator implicado na reflexão, um tipo de cooperação que acaba por se tornar estimulante para todos os participantes.

Ainda acerca da colaboração mútua entre pesquisadores e autores, Franco (2005) afirma que o exercício da pesquisa-ação como investigação formativo-emancipatória requer fundamentalmente o modelo do agir comunicativo: interativo, que nasce do coletivo, da equipe. Para Morin (2004), a pesquisa-ação é um fenômeno educativo e o que possibilita a aprendizagem neste contexto é a comunicação. Considerando também a importância da comunicação entre pesquisadores e participantes em pesquisa-ação, Dionne, respaldado em Descarries e Corbell, apresenta alguns "parâmetros comunicacionais":

- o compartilhamento de representações comuns no que diz respeito aos fundamentos da pesquisa-ação e à ideologia subjacente;

- as capacidades de comunicação interpessoal, a saber, as aptidões de abertura e empatia;

- o engajamento e a implicação por parte da pesquisadora e do grupo;

- a aceitação da negociação no processo de pesquisa e a consideração das restrições de ambos os lados; 
- $\quad$ a identificação de zonas de interesses em comum (DESCARRIES; CORBELL, 1993, p. 28 apud DIONNE, 2007, p. 69-70).

Um equívoco possível a partir dessa perspectiva de pesquisa é achar que o pesquisador não tem lugar estabelecido. Segundo Dionne (2007), na pesquisa-ação o ator está sempre presente e isso não impede que o pesquisador deixe de aplicar as regras do processamento de dados e sua presença é percebida como contribuição para definir certas prioridades de análise com vista à utilização dos resultados. O processamento de dados é realizado numa dinâmica de trocas, de diálogo, de debate com os parceiros sociais. Os procedimentos de análise são mais vivos, em constante confrontação com a realidade dos atores sociais.

Também sobre o lugar do pesquisador, Thiollent (1996) apresenta que os pesquisadores mais tradicionais geralmente possuem uma postura unilateral. Eles consideram que os membros das classes populares não sabem nada, não têm cultura, não têm educação, não dominam raciocínios abstratos, só podem dar opiniões e os especialistas, por sua vez, sabem tudo e nunca erram. E para superar esse tipo de postura, Morin (2004) estabelece como comportamentos do pesquisador: estar aberto, disponível, atento e à escuta dos outros.

Costa et al. (2008), por sua vez, reforçam que investigar a partir da pesquisa-ação, principalmente em situações- limite de sofrimento extremo, leva o pesquisador para o centro de um turbilhão e de caos psíquico-emocional, apresentando-lhe impasses no planejamento metodológico, mobilizações subjetivas e conflitos éticos-morais. Ao mesmo tempo, para seguir desempenhando da melhor maneira seu papel de pesquisador e profissional, esse turbilhão leva-o a criar saídas nas diversas frentes de obstáculos para tentar contorná-los. As autoras apontam também que o trabalho em redes sociais é uma estratégia adequada para a criação dessas saídas. Para elas, a implicação que ocorre na pesquisa-ação deve ser direcionada para ampliar a capacidade de compreensão e intervenção e não o contrário. Nogueira e Sá (2004 apud COSTA et al. 2008) descrevem que é impossível ficar imune ao conteúdo tratado na pesquisa-ação sobre determinados temas e em determinados contextos, e é isso que faz com que a emoção se torne fonte de aproximação da dor alheia, desencadeadora de conhecimento e também de ação.

\section{Processo de desligamento no Contexto da Pesquisa-aÇão}

A discussão sobre a relação pesquisador-participantes é condição para que exista a pesquisa-ação e serve como parâmetro para a sua realização. É conhecido que a vinculação entre as pessoas, a cooperação, a participação de todos os envolvidos é condição para a realização da pesquisa-ação. Dessa forma, o início e o meio da pesquisa são considerados e discutidos com frequência pelos autores estudados. Mas, e o final da pesquisa? Como acontece a separação? Como se dá a desvinculação? 
A definição de desligamento no contexto da pesquisa-ação aqui estudado tem uma conotação particular. $\mathrm{O}$ desligamento refere-se ao processo de separação entre pesquisadores e atores que leva ao encerramento da pesquisa. Em outros contextos terapêuticos, essa separação é também chamada de "suspensão de serviço" ou "encerramento das atividades".

O pesquisador e os participantes estão implicados no processo de construção do conhecimento em pesquisa-ação e por isso, é preciso considerar que essa implicação se dá do início ao fim do processo investigativo. Nesse sentido, a maneira como se encerra uma pesquisa-ação está relacionada ao processo de construção da própria pesquisa. Conforme descreve Dionne (2007, p. 53):

Na pesquisa-ação, o ator está sempre presente. Isso não
significa que o pesquisador possa deixar de aplicar as regras
do processamento de dados, mas sua presença é percebida
como contribuição para definir certas prioridades de análise
com vista à utilização dos resultados. O processamento de
dados é realizado numa dinâmica de trocas, de diálogo,
de debate com os parceiros sociais. Os procedimentos de
análise são mais vivos, em constante confrontação com a
realidade dos atores sociais.

Devido a essa presença constante do ator e do pesquisador, Franco (2005) descreve que a pesquisa-ação bem realizada só é possível quando conta-se com um longo tempo para sua realização plena. Dessa forma, esse tipo de pesquisa não pode ser um processo rápido, superficial, com tempo marcado, pois a imprevisibilidade é um componente fundamental à prática da pesquisa-ação.

Outro componente importante para a pesquisa-ação, conforme aponta Morin (2004), é a negociação entre pesquisador e participantes que deve estar presente do início ao final da pesquisa. Para Morin (2004), no plano da cogestão, espera-se que todas as decisões, para as diferentes tarefas de pesquisa e de ação, inclusive a respeito do encerramento das atividades, sejam tomadas por todos os atores. Esse é, segundo o autor, o nível mais difícil de ser alcançado porque é considerado obrigação de decisão coletiva, às vezes, mesmo nos menores detalhes.

Barbier (2007), a partir de uma perspectiva mais acadêmica, também apresenta considerações sobre o final da pesquisa-ação. No entanto, para ele, o foco está na ideia de que o objeto final da pesquisa-ação existencial, modalidade defendida pelo autor, reside em uma mudança de atitude do sujeito (indivíduo ou grupo) em relação à realidade que se impõe em última instância. Mas não se trata, de esperar uma mudança milagrosa ou de permanecer numa atitude passiva.

De acordo com Barbier (2007), na pesquisa-ação, a interpretação e a análise presentes nas últimas fases descritas, são produto de discussões de grupo. Isso exige uma linguagem acessível para todos. $\mathrm{O}$ traço principal da pesquisa-ação impõe a comunicação dos resultados da investigação aos membros nela envolvidos, objetivando a análise de suas reações, que também é informação de pesquisa. A pesquisa-ação, dessa maneira, submete seus resultados, previamente 
negociados dia a dia entre o pesquisador e os participantes da pesquisa, a toda a coletividade para provocar sua avaliação. A coletividade, segundo Barbier (2007) passa, então, à determinação das "possibilidades de melhoria". No fim da pesquisa, pode ou não haver a redação de um relatório final, mas, de qualquer modo, há sempre discussão sobre os resultados e uma proposta de novas estratégias de ação. Assim, havendo necessidade, há ação. Para ilustrar essa continuidade, o autor apresenta o método cíclico e espiral em pesquisa-ação de Kurt Lewin: planejamento; ação; observação; e reflexão; depois um novo planejamento da experiência em curso. Por isso, a pesquisa-ação existencial é um modelo aberto da pesquisa-ação que se organiza em torno de dois eixos: a implicação e o distanciamento, o mundo e os outros.

Ao escrever sobre a quinta etapa da pesquisa-ação, a fase de análise e avaliação dos resultados, Dionne (2007) também afirma que há nesse momento análise e redação do relatório de pesquisa, que em pesquisa-ação também é realizada com os atores da ação. Para o autor, as divergências de interpretação podem também alimentar a discussão e favorecer uma compreensão mais fidedigna da situação. O cuidado que se deve ter é não permitir que se perca a eficiência da ação e a cientificidade da pesquisa. Nessa etapa, segundo Dionne (2007), observa-se melhor como o pesquisador torna-se ator e como o ator torna-se pesquisador.

Especificamente sobre a finalização e reativação da ação, Dionne (2007) afirma que a última fase se distingue da precedente na medida em que permite a possível "saída" dos pesquisadores e atores do processo de pesquisa-ação realizada. Mesmo que várias operações anteriormente evocadas tenham permitido progressivamente a possível saída dos participantes (pesquisadores e participantes-atores), é útil lembrar brevemente seu alcance. Como a pesquisa-ação consiste em um processo de intervenção, é evidente que a questão da continuação da ação sempre deve estar colocada como possível, da mesma maneira que é apresentado por Barbier (2007)

Somado a isso, Dionne (2007, p. 121) argumenta sobre a necessidade de o pesquisador ser capaz de sair do processo, se necessário:

É importante que cada membro da equipe de pesquisaação possa apontar as possíveis rupturas a efetuar com as pessoas implicadas no processo. A pesquisa pode continuar sob outras formas, com outros pesquisadores, ou mesmo outros atores podem vir a participar. De acordo com a experiência, é difícil decidir sobre a finalização de um processo de pesquisa-ação. Isso é provavelmente verdade em toda intervenção social! É importante se proteger e poder decidir sobre as implicações futuras. É preciso voltar aos objetivos e aos compromissos iniciais para se adaptar às circunstancias. Também é importante voltar ao documento de orientação para facilitar as rupturas a realizar. 
Thiollent e Silva (2007), em um trabalho com famílias na área de gestão de problemas ambientais, também caracterizam o final da pesquisa como o momento da devolutiva. Nesse instante, organizada a devolutiva com as famílias entrevistadas, cada comunidade pode discutir o resultado da pesquisa e priorizar os temas de seu interesse. Ainda sobre essa "devolutiva", para Barbier (2007), o pesquisador não apresenta sozinho seu relatório de pesquisa ao solicitante da pesquisa (laboratório de pesquisa, órgão público, etc.), sem antes o ter apresentado ao seu grupo de pesquisa de campo, principal interessado. Quando possível, de acordo com o autor, é mais interessante que o relatório seja redigido coletivamente.

Ao buscar uma conclusão sobre a devolutiva em pesquisa-ação, discutida pelos diversos autores estudados neste trabalho, Thiollent (1996) afirma que é desejável haver um retorno da informação entre os participantes que conversaram, participaram, investigaram, agiram, etc. Esse retorno objetiva promover uma visão de conjunto. É difícil imaginar um indivíduo que esteja participando do processo tenha espontaneamente acesso ao conjunto. Os canais de divulgação, sobretudo os informais, são aproveitados para fortalecer a tomada de consciência do conjunto da população interessada (não limitada aos participantes efetivos). A tomada de consciência se desenvolve quando as pessoas descobrem que outras pessoas ou outros grupos vivem mais ou menos a mesma situação.

De maneira conclusiva e na busca de uma síntese possível, Barbier (2007) apresenta que uma pesquisa-ação chega ao fim quando o problema inicial é resolvido, se é que pode realmente sê-lo. Por isso, somente os participantes ligados ao problema podem por fim refletir e discutir sobre a resolução. Ainda por meio de uma perspectiva acadêmica de pesquisa-ação, Barbier (2007) afirma algo aparentemente inexistente nas obras dos outros autores estudados, que diz respeito à possibilidade dos pesquisadores profissionais decidirem que o encerramento se aproxima por razões de tempo, dinheiro ou outra implicação, mas somente os participantes devem ter a última palavra na discussão sobre a viabilidade da continuação da pesquisa, por meio da construção de alternativas possíveis. Um meio alternativo, não só neste caso, é trabalhar em conjunto com as redes sociais, ou redes de apoio, conforme descreve Ude (2002), ligadas ao grupo estudado.

Como apresentado, o processo de desligamento no contexto da pesquisa-ação é marcado pela presença atuante dos pesquisadores e dos participantes. Tal atuação comparece, para os autores estudados, ora na análise da mudança, da resolução dos problemas levantados, das informações construídas, como no momento da escrita do relatório final. Chama a atenção, no entanto, o fato de que, para os autores estudados, o encerramento da pesquisa é também uma decisão a ser tomada coletivamente. Ao revisitar as origens e ao desenvolvimento da pesquisa-ação, essa ideia é clarificada, pois seria incoerente desconsiderar a atuação dos participantes neste momento. 


\section{Considerações Finais}

A dinâmica da pesquisa-ação depende da qualidade do vínculo humano estabelecido entre pesquisadores e participantes. Por esse motivo, a ligação e o processo de desligamento devem ser considerados no processo e assim, durante toda a construção da pesquisa-ação que se pretende realizar.

Os autores estudados apresentam diferentes contribuições para o entendimento do histórico, dos conceitos, formas de realizá-la, mas trazem apenas algumas considerações semelhantes sobre o processo final da pesquisa-ação. Mesmo em menor quantidade, tais contribuições são importantes para o início da compreensão e comprometimento com essa perspectiva de pesquisa e com os participantes envolvidos.

As principais contribuições dos autores estudados sobre o processo de desligamento estão relacionadas à última fase de construção da pesquisa-ação. Essa fase é, por sua vez, marcada pelo encerramento, retorno da informação ou "devolutiva" e escrita do relatório final, que promove uma visão de conjunto da própria pesquisa. Principalmente para Barbier (2007), a pesquisa-ação chega ao final quando o problema inicial é resolvido, ou ao menos encaminhado para que aconteça a resolução, uma vez que a pesquisa sozinha pode não dar conta de resolvê-lo pelos mais diversos motivos. Segundo os autores estudados, em todo esse processo de encerramento, a negociação entre pesquisadores e participantes deve existir. Dessa forma, é possível conceber o encerramento das atividades como parte da própria pesquisa-ação.

Não considerar o processo de encerramento da pesquisa-ação parece ser um retorno à relação sujeito-objeto no contexto da ciência, e assim, se contrapor à própria pesquisa-ação. Os participantes possuem demandas que precisam sempre ser consideradas, para além da necessidade do próprio pesquisador. Dessa maneira, não atuar a fim de promover a autonomia dos participantes, durante e na medida do possível, depois da pesquisa, seria como "usá-los", tratá-los como objetos e estabelecer possíveis relações de dependência. Por isso uma alternativa importante e compromissada, quando a realidade do pesquisador impõe o término, contrariando a necessidade do grupo, é fazer algo que já esteve presente há algum tempo na psicologia, mas agora resgatado com mais contextualização e menos reducionismos: encaminhar, trabalhar em rede, ampliar as possibilidades de benefícios aos participantes.

Por outro lado, cabe indagar se os modelos que têm inspirado a prática do psicólogo em contextos da pesquisa-ação, basicamente em contextos comunitários ou de serviços psicossociais, não têm sido aqueles da psicologia clínica tradicional no seu sentido restrito, levando-o a supor que deve prestar um atendimento psicológico nos moldes daquele realizado em consultórios. Tal equívoco tem rendido igualmente orientações de políticas governamentais em nível federal (vide documentos norteadores do Ministério do Desenvolvimento Social/Secre- 
taria Nacional de Assistência Social) que contraindicam equivocadamente a perspectiva terapêutica em detrimento da abordagem clínica no direcionamento do trabalho psicossocial nos centros de referência de assistência social.

Há, dessa forma, para além deste trabalho, a necessidade de construções referenciais sobre o processo de desligamento entre participantes e pesquisadores em diferentes modalidades de pesquisa-ação. E assim promover benefícios sem fomentar a dependência emocional em trabalhos em que a implicação é considerada necessária para o processo de mudança.

\section{REFERÊNCIAS}

BARBIER, R. A Pesquisa-ação na instituição educativa. Tradução de Estela dos Santos Abreu. Colaboração de Maria Wanda Maul de Andrade. Rio de Janeiro: Zahar, 1985.

BARBIER, R. A pesquisa-ação. Tradução de Lucie Dibio. Brasília: Liber Libro, 2007.

COSTA, L. F. et al. O desafio da supervisão e pesquisa-ação em casos de abuso sexual: os professores e suas questões. Paidéia, Ribeirão Preto (SP), v. 18, n. 40, p. $355-370,2008$.

BRANDÃO, C. R. Participar-Pesquisar. In: Participante. São Paulo: Brasiliense, 1987. p. 7-14. . Repensando a Pesquisa

DEMO, P. Elementos metodológicos da pesquisa participante. In: BRANDÃO, C. R. (Org.). Repensando a Pesquisa Participante. São Paulo: Brasiliense, 1987. p. 104- 130 .

DEMO, P. Pesquisa Participante: saber pensar e intervir juntos. Brasília: Liber Livro, 2004.

DIONNE, H. A Pesquisa-ação para o Desenvolvimento Local. Tradução de Michel Thiollent. Brasília: Liber Livro, 2007.

FRANCO, M. A. S. Pedagogia da Pesquisa-ação. Educação e Pesquisa, São Paulo, v. 31, n. 3, p. 483-502, set./dez. 2005.

MIRANDA, M. G. de; RESENDE, A. C. A. Sobre a pesquisa-ação na educação e as armadilhas do praticismo. Revista Brasileira de Educação, Rio de Janeiro, v. 11, n. 33, p. 511- 518, set./dez. 2006.

MORIN, A. Pesquisa-ação integral e sistêmica: uma antropedagogia renovada. Tradução de Michel Thiollent. Rio de Janeiro: DP\&A, 2004. 
THIOLLENT, M. Notas para o debate sobre pesquisa-ação. In: BRANDÃO, C. R. (Org.). Repensando a Pesquisa Participante. São Paulo: Brasiliense, 1987. p. 82-103.

THIOLlENT, M. Metodologia da Pesquisa-ação. São Paulo: Cortez, 1996.

THIOllent, M. Prefácio. In: DIONNE, H. A Pesquisa-ação para o Desenvolvimento Local. Tradução de Michel Thiollent. Brasília: Liber Livro, 2007.

THIOLLENT, M.; SILVA, G. de O. Metodologia de pesquisa-ação na área de gestão de problemas ambientais. RECUS- Revista Eletrônica de Comunicação, Informação e Inovação em Saúde, Rio de Janeiro, v. 1, n. 1, p. 93-100, jan./jun. 2007.

TRIPP, D. Pesquisa-ação: uma introdução metodológica. Educação e Pesquisa, São Paulo, v. 31, n. 3. p. 443-466, set./dez. 2005.

UDE, W. Redes Sociais: possibilidade metodológica para uma prática inclusiva. In: CARVALHO, A.; SALlES, F.; GUIMARÃES, M.; UDE, W. (Org.). Políticas Públicas. Belo Horizonte: UFMG, 2002. p.127-139.

Recebido em: 26 de julho de 2010 Aceito em: 21 de novembro de 2012 